\title{
ENCAPSULAÇÃO DO ÓLEO DE NEEM PELA TÉCNICA DE MINIEMULSIFICAÇÃO/EVAPORAÇÃO DO SOLVENTE
}

\section{Juliana D. Z. Boaventura*, Joice P. Bigon, Liliane M. F. Lona.}

\section{Resumo}

O óleo de neem foi encapsulado em nanopartículas de poli(ácido lático-co-ácido glicólico) (PLGA) pelo método de miniemulsificação/evaporação do solvente, e estas foram caracterizadas em análises de FTIR, DSC, TGA e tamanho de partícula. Resultados mostraram que as nanopartículas formadas sao estáveis ao longo do tempo e que o óleo foi encapsulado dentro da matriz polimérica sem alteração das características químicas dos compostos.

\section{Palavras-chave:}

Nanopartículas, óleo de neem, miniemulsificação

\section{Introdução}

O óleo de neem apresenta propriedades inseticidas, antifúngicas e antibacterianas ${ }^{1}$. Suas moléculas possuem grande quantidade de duplas ligações, tornando-o suscetivel à degradação².

Nanopartículas poliméricas (NPs) podem prevenir a degradação do ativo encapsulado ${ }^{3}$. Uma das técnicas de obtenção das NPs é a miniemulsificação/evaporação do solvente.

O objetivo deste trabalho foi a encapsulação do óleo de neem em nanopartículas de PLGA através da técnica de miniemulsificação/evaporação do solvente $e$ caracterização quanto às suas propriedades físicas.

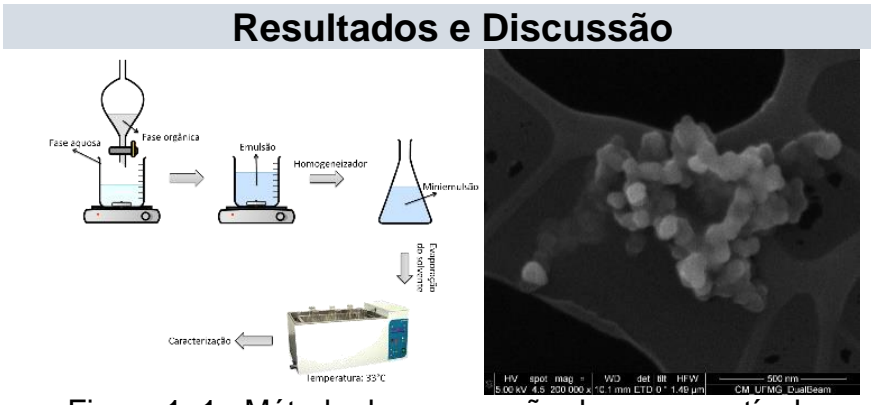

Figura 1: 1a Método de preparação das nanopartículas poliméricas. $1 \mathrm{~b}$ Imagem de microscopia eletrônica de transmissão.

Tabela 1. Diâmetro médio, índice de polidispersidade (PDI) e potencial zeta das nanopartículas.

\begin{tabular}{|c|c|c|c|}
\hline $\begin{array}{c}\text { Experi- } \\
\text { mento }\end{array}$ & Surfactante & PDI & $\begin{array}{c}\text { Potencial } \\
\text { Zeta }(\mathrm{mV})\end{array}$ \\
\hline 1 & SDS & $0,12 \pm 0,01$ & $-39,5 \pm 0,5$ \\
\hline 2 & Lecitina & $0,06 \pm 0,02$ & $-36,1 \pm 0,8$ \\
\hline 3 & Lecitina & $0,076 \pm 0,02$ & $-41,8 \pm 0,5$ \\
\hline 4 & SDS & $0,105 \pm 0,03$ & $-42,3 \pm 0,4$ \\
\hline
\end{tabular}

O baixo PDI mostrado na tabela 1 indica um sistema monodisperso e o potencial zeta negativo acima de 30 em módulo, indica uma boa estabilidade das miniemulsões.

Os experimentos 3 e 4 foram formulados com metade da concentração de óleo de Neem em relação a 1 e 2.

Conforme a figura 2a indica, a decomposição de PLGA começa em $272^{\circ} \mathrm{C}$. Já o começo da perda de massa das NPs contendo o óleo diminui para $250^{\circ} \mathrm{C}$. Essa redução pode ser explicada devido a presença de óleo na nanopartícula, pois a decomposição do óleo começa em $245^{\circ} \mathrm{C}$.

$\mathrm{Da}$ figura $2 \mathrm{~b}$ nota-se que as NPs com lecitina apresentam tamanhos maiores do que as com SDS para a mesma concentração.
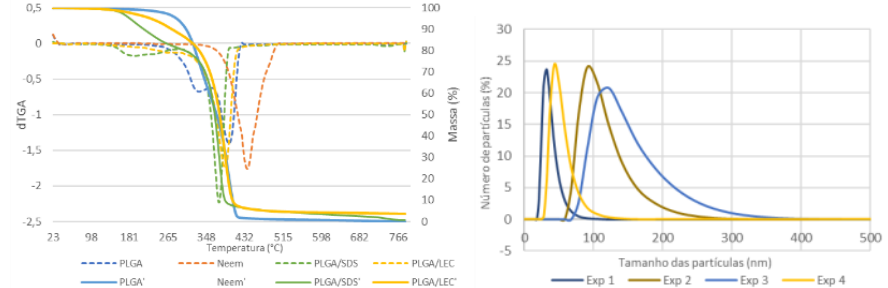

Figura 2. 2a indica as análises termogravimétricas (TGA) e $2 b$ tamanho de partícula, respectivamente.

Além disso, análises de calorimetria exploratória diferencial (DSC) e de espectroscopia no infravermelho mostraram que não houve deformação ou mudanças nas estruturas das nanopartículas formadas, e por isso, as características químicas das amostras permaneceram inalteradas.

\section{Conclusões}

Notou-se o aumento do tamanho das NPs com o uso do surfactante lecitina, em relação ao SDS; e houve homogeneidade no tamanho das partículas formadas.

Análises de DSC mostraram que não houve interferência do óleo na temperatura de transição vítrea e as de TGA confirmaram a presença de óleo nas nanopartículas. Verificou-se que nanopartículas estáveis contendo óleo de Neem podem ser formadas utilizando a técnica de miniemulsificacao/evaporação do solvente

\section{Agradecimentos}

A Faculdade de Engenharia Química da Universidade Estadual de Campinas e ao Conselho Nacional de Desenvolvimento Científico e Tecnológico (CNPq).

${ }^{1}$ Brahmachari, Goutam. Neem-An Omnipotent Plant: A Retrospection. ChemBioChem. 2004, 5, 408-421.

${ }^{2}$ A. Adhvaryu, S.Z. Erhan, Z.S. Liu, J.M. Perez. Oxidation kinetic studies of oils derived from unmodified and genetically modified vegetables using pressurized differential scanning calorimetry and nuclear magnetic resonance spectroscopy. Thermo. Acta, 2000, 364, 87-97.

${ }^{3}$ Antonietti, M; Landfester, K. Polyreactions in miniemulsions. Progress in Pol. Sci., 2002, 27, 4, 689-757. 